\section{USO DAS ÁREAS DE RESERVA LEGAL E DE PRESERVAÇ̃̃O PERMANENTE EM ASSENTAMENTOS RURAIS DO SEMIÁRIDO}

Roberto de Sousa Miranda Roaga Bezerra e Silva ${ }^{2}$

Resumo: A proposta desse trabalho é analisar o uso das Áreas de Reserva Legal e de preservação permanente dos assentamentos rurais Jacu, criado pelo INCRA, e São João II, implementado pelo crédito fundiário, localizados no município de Pombal (PB), bem como verificar os impactos socioeconômicos dessas áreas sobre a produção agropecuária, ressaltando a quantidade e valor da produção agropecuária familiar, observando as práticas socioambientais das famílias assentadas, suas interlocuções com os órgãos públicos responsáveis pela organização das áreas reformadas e pela fiscalização ambiental. A chave de análise utilizada foi a ecologia política, que destaca as relações entre poder e processos de mudança ambiental. A metodologia foi orientada pela aplicação de questionários e a realização de entrevistas semiestruturadas com assentados e conversas informais com agentes do IBAMA, INCRA e Projeto Cooperar. Os dados de pesquisa nos mostraram que a maior parte das terras cultivadas pelos agricultores familiares se localizam em áreas de preservação permanente, que as áreas de reserva legal são utilizadas para a pecuária e que faltam recursos humanos e infraestrutura adequada para que haja fiscalização ambiental e ações educativas.

Palavras-chave: Agricultura Familiar; Assentamentos Rurais; Áreas de Reserva Legal; Áreas de Preservação Permanente; Semiárido.

\footnotetext{
Doutor em Ciências Sociais. Professor do Programa de Pós-Graduação em Ciências Sociais da Universidade Federal de Campina Grande.

${ }^{2}$ Graduada em Engenharia Ambiental pela Universidade Federal de Campina Grande.
}

Abstract: The purpose of this work is to analyze the use of the legal reserve and permanent preservation areas of the rural settlements Jacu, created by INCRA, and São João II, implemented by the land credit, located in the municipality of Pombal (PB), as well as verify the impacts socioeconomic aspects of agricultural and livestock production, highlighting the quantity and value of family farming production, observing the social and environmental practices of the settled families, their interaction with the public agencies responsible for the organization of the reformed areas and environmental inspection. The key of analysis used was political ecology, which highlights the relationship between power and processes of environmental change. The methodology was guided by the application of questionnaires and the conduction of semi-structured interviews with settlers and informal conversations with agents of IBAMA, INCRA and Project Cooperar. Research data showed us that most of the land cultivated by family farmers is located in permanent preservation areas, that legal reserve areas are used for livestock and that there is a shortage of human resources and adequate infrastructure for environmental inspection and actions Education.

Keywords: Family farming; Rural Settlements; Legal Reserve Areas; Areas of Permanent Preservation; Semiarid.

\section{Introdução}

A modernização e a industrialização da agricultura nos anos 1970 provocaram alterações nas relações com a natureza, por conta de uma mudança dos processos técnicos de produção e pela intensiva ocupação do espaço mediante a especialização dos processos produtivos. Os solos foram erodidos em função do manejo inadequado, os ecossistemas simplificados em função de uma exploração intensiva e especialização dos cultivos, as florestas dizimadas indiscriminadamente, como resultante da expansão de fronteiras agrícolas, todos os recursos foram atingidos (BRANDENBURG, 2010).

Os impactos associados à modernização da agricultura consistiram em uma série de mudanças sociais e políticas, que reestruturaram o eixo de poder e a correlação de forças locais e regionais e ressignificaram a grande propriedade rural. Para as famílias sem terra, desde então, a conquista do acesso a terra passou a representar a materialização do direito à moradia, ao trabalho e a oportunidade de trabalhar para si próprio, o que lhes dá uma 
condição de liberdade e, consequentemente, melhoria na qualidade de vida.

Deste modo, as análises das questões ambientais no mundo rural não podem se resumir à reorganização técnica dos processos produtivos. Se há uma preocupação em restaurar processos produtivos que procuram gerir recursos naturais, é possível dizer que a preocupação com o meio ambiente se amplie e, desta forma, outros aspectos passem a ser considerados na reorganização da agricultura e do espaço rural. A conservação dos recursos florestais e hídricos não apenas fazem do rural um meio reorganizado de produção agrícola, como também um espaço de consumo ambiental (BRANDENBURG, 2005).

No que tange aos desafios relacionados à conversão dos latifúndios em assentamentos rurais se destaca a dificuldade de promover o desenvolvimento do processo produtivo e a geração de renda sem causar danos ao meio ambiente (MIRANDA e CUNHA, 2011). O comprometimento com a sustentabilidade é um processo cheio de limitações, em virtude da pouca disponibilidade de recursos financeiros e ao fato das famílias cultivarem em Áreas de Reserva Legal (ARLs) e/ou Áreas de Preservação Permanente (APPs), utilizando agrotóxicos, o que compromete os recursos solo e água (CASTRO e GOMES, 2007).

A compreensão do uso e do manejo dos recursos naturais em áreas reformadas no Semiárido nordestino passa pela análise da relação entre as estratégias produtivas, utilizadas pelos assentados, e os processos de mudança ambiental nos assentamentos. É preciso entendê-los como resultado de escolhas, individuais ou coletivas tomadas em condições específicas de mercado, tecnologia, crédito, projetos produtivos e de vida e nas inter-relações com outros atores sociais, especialmente, com os agentes públicos e as lideranças de movimentos sociais (CUNHA e NUNES, 2008).

Outra questão que merece destaque é o fato da conservação ambiental, como prevista no Código Florestal Brasileiro, gerar encargos exclusivamente aos produtores rurais, ao passo que os benefícios se estendem à toda a sociedade, podendo ultrapassar as fronteiras nacionais. As ARLs têm impacto diferenciado nos produtores rurais, os pequenos e médios proprietários, com menor disponibilidade de terras seriam os mais afetados (CAMPOS e BACHA, 2016). Para a elaboração de políticas públicas eficazes, é preciso conhecer as consequências da implementação da legislação ambiental pelos produtores de diversas características, com diferenciada situação de recursos (FASIABEN, 2011).
Embora as ARLs e as APPs sejam de uso restrito e não suscetíveis ao uso produtivo, na realidade, transformam-se em áreas exploradas e/ou manejadas de modo inadequado, atendendo às necessidades reprodutivas dos assentados. As incertezas quanto ao manejo dentro das possibilidades e impossibilidades definidas pela legislação, a falta de conhecimentos técnicos, ausência e/ou ineficiência de assistências técnicas em suprir as demandas, o desconhecimento sobre formas de manejo adequado de novos produtos de procedência florestal, madeireiros ou não, são fatores que podem estar relacionados ao descumprimento da lei em assentamentos rurais (MIRANDA e CARMO, 2009).

Neste contexto, o objetivo do artigo é analisar os impactos socioeconômicos da produção agropecuária familiar nas ARLs e nas APPs dos assentamentos rurais Jacu e São João II, localizados na Mesorregião do Sertão Paraibano, no município de Pombal (PB), mapear as atividades desenvolvidas nessas áreas, ressaltando a quantidade e valor da produção e observar as interlocuções das famílias assentadas com o Instituto Nacional de Colonização e Reforma Agrária (INCRA), o Instituto Brasileiro do Meio Ambiente e dos Recursos Naturais Renováveis (IBAMA), e o Projeto Cooperar.

Parte-se de duas hipóteses: (1) que os órgãos públicos responsáveis pela execução dos programas de reestruturação fundiária no Brasil estão ligados, direta ou indiretamente, aos processos de degradação das ARLs e APPs, pelo rigor da legislação ambiental e pela leniência dos agentes dos órgãos oficiais de fiscalização ambiental; (2) que a grande maioria das terras efetivamente cultivadas pela agricultura familiar no Sertão paraibano estão inseridas em APPs, o que ocorre, em parte, pela escassez de chuvas e pela possibilidade de desenvolver a pecuária e atividades irrigadas nas margens de rios e açudes.

A pesquisa foi desenvolvida no período de julho de 2013 a julho de 2014 , em dois momentos. O primeiro teve como foco os assentamentos rurais Jacu e São João II, para analisar os impactos socioeconômicos das ARLs e das APPs sobre a produção agropecuária. O segundo se deteve na análise da interlocução entre os agentes do INCRA, IBAMA e Projeto Cooperar com as famílias assentadas e em que medida essas ações afetam as práticas socioambientais dos assentados.

Fez-se uma revisão bibliográfica, leitura e análise de livros, artigos, dissertações e teses, sobre a questão ambiental no meio rural, bem como uma análise das principais leis que compõem a temática ambiental e 
focam a sua influência e atuação no meio rural. Posteriormente, fez-se o levantamento das atividades agropecuárias desenvolvidas nas ARLs e nas APPs, mediante a aplicação de questionários a todas famílias assentadas, a realização de entrevistas semiestruturadas com assentados que aceitaram conversar, observações in lócus e consulta às atas das associações dos dois assentamentos.

Com o auxílio de ferramentas e técnicas de geoprocessamento mapeou-se as ARLs e as APPs dos assentamentos. A coleta de dados foi feita com o GPS (Global Positioning System), de marca Garmim e modelo GPSmap 76CSx Para os mapas foi utilizado o software ArcGis 9.3, usando principalmente a extensão ArcMap, que serve para a confecção de diferentes mapas. Por fim, realizou-se visitas à Superintendência Regional do INCRA na Paraíba, à Superintendência do IBAMA em João Pessoa (PB) e ao Escritório do Projeto Cooperar em Pombal (PB) para observar como se dá a comunicação entre diferentes instâncias dos órgãos e como é a interlocução com os assentados, quando são realizadas ações de fiscalização ambiental.

\section{Ecologia Política e Relações de Poder}

A ecologia política têm tratado de quatro temas: a ideia de que a utilização dos recursos naturais é organizada por relações sociais que pressionam o meio ambiente; o reconhecimento da pluralidade de posições, interesses e racionalidades sobre o ambiente, de modo que o lucro de uma pessoa pode representar a pobreza de outra; a ideia de uma conexão global através da qual os processos políticos e econômicos externos estruturam e são estruturados pelas questões locais; e a defesa de que a degradação da terra é um resultado e uma causa da exclusão social (GEZON e PAULSON, 2004).

A crescente importância das questões ambientais nas lutas sociais e nas pesquisas que enfatizam amplamente as diferentes relações entre grupos humanos e seus ambientes biofísicos motivaram sérias reflexões sobre os conceitos e métodos da ecologia política. Alguns ecologistas políticos têm procurado olhar para além da comunidade local, para explicar o acesso e uso de recursos naturais, as práticas de grupos sociais diferenciados pela raça, etnia ou gênero e suas interações cotidianas nos espaços políticos formais (GEZON e PAULSON, 2004; CUNHA, 2004).

Embora a análise das dinâmicas locais seja indispensável, é preciso introduzir o conceito de poder para se apreender os conflitos, referentes à apropriação e uso de recursos naturais, e as mudanças ambientais desencadeadas (GREENBERG, 1994). Nesse sentido, o estudo das relações entre sociedades e naturezas não podem ser apenas reflexões particulares e românticas, como o fazem os ecologistas normativos (GÖRG e BRAND, 2000, GARI, 2000, BELMONTE, 2004), mas uma reflexão que trate o poder enquanto mediador dessas complexas relações (ALIMONDA, 2007).

Ao enfatizar os processos decisórios e o contexto social e econômico que moldam políticas e práticas ambientais, a ecologia política se detém à distribuição e controle dos recursos naturais. Em termos metodológicos faz um mapeamento das fontes de oposição política aos projetos de apropriação dos recursos naturais, que parte do pressuposto de que os recursos naturais são construídos pela dinâmica de circulação de poder entre os diferentes grupos sociais (CUNHA, 2004, MIRANDA, 2013).

Os esforços dos ecologistas políticos em incorporar as relações de poder em suas análises não podem ser desconsiderados, no entanto, a maneira como o poder é problematizado o torna abstrato, não fica explícito quem são os atores sociais que estão ligados aos conflitos e processos de mudança ambiental. Os pesquisadores se referem a segmentos da sociedade, grandes produtores e populações tradicionais, mas não os apresentam, não destacam quem são os indivíduos que compõem o grupo, as relações de interdependência e as tensões internas (MIRANDA, 2011).

A adoção da definição de poder de Elias (2001) afasta a ecologia política das orientações normativas e fornece as ferramentas teóricas e metodológicas para a investigação das relações socioeconômicas associadas à apropriação de recursos naturais e aos processos de mudança ambiental, porque os indivíduos não são apresentados como seres totalmente fechados em si mesmos, mas interdependentes, compondo figurações que podem ser observadas e comprovadas empiricamente, podendo, assim, precisar o nascimento e desenvolvimento de figurações específicas.

Em termos analíticos, o estudo de uma figuração não pode ser dissociado das categorias de interdependência, função (compreendida de modo relacional, pois só podemos falar em função quando falamos de interdependências que constrangem pessoas, umas mais outras menos) e coerção, e centra-se na compreensão dos condicionamentos que os seres humanos estabelecem mutuamente e nas transformações que sofrem, individualmente ou em grupo, devido ao aumento ou à redução de suas interdependências e às variações de poder (QUINTANEIRO, 2006).

Os processos de mudança numa figuração são explicados a partir de 
modelos abrangentes que mapeiem, temporal e espacialmente, as relações sociais, econômicas, políticas e culturais de um grupo ou sociedade, permitindo, assim, a compreensão das relações de interdependência existentes entre os diferentes grupos sociais e no interior destes. Descobertas as interdependências, a identidade última dos indivíduos que formam a figuração pode ser reproduzida (ELIAS, 2001)

O declínio e a ascensão de um grupo social dentro da figuração são determinados pelas correlações de forças produzidas pelas relações de interdependências entre os diferentes grupos sociais e no interior destes. Quando o balanço de tensões da figuração de indivíduos é alterado, devido às tensões e aos conflitos entre os grupos sociais e entre os membros do grupo, ocorre uma movimentação no interior da figuração (ELIAS, 2001), marcada pela redefinição das posições sociais e dos projetos políticos e econômicos.

As formas de dominação são resultantes de lutas sociais que estabilizam, por um momento, a distribuição de poder (ELIAS, 2001). Apesar do processo de dominação consolidar um modo de partilha do poder, ainda assim haverá um equilíbrio instável de tensões enquanto existir uma interdependência funcional entre as pessoas, mesmo que as diferenças de poder sejam grandes, porque o poder não é como amuleto, que um indivíduo possui e outro não, é intrínseco às relações humanas (ELIAS 2005).

A noção de poder de Elias $(2001,2005)$ permite à ecologia política articular a natureza e a política, sem sobreposições, a partir da análise das relações de interdependência existentes entre os diferentes grupos sociais, locais, regionais, nacionais e internacionais, defensores de estratégias de apropriação de recursos naturais num determinado espaço que se confrontam. Muitos ecologistas políticos enfatizam apenas uma destas dimensões, como destacam Vayda e Walters (1999) e Latour (2004).

\section{Assentamento Rural Jacu}

$\mathrm{O}$ assentamento Jacu ocupa uma área de 1.340ha (Figura 1) e foi implementado pelo INCRA, através da Portaria n. ${ }^{\circ} 11$, de 16 de Junho de 2003. Ao todo, 40 famílias foram assentadas, cada uma ocupa um lote de 14,5ha. A organização do assentamento e a interlocução com órgãos públicos é articulada por uma associação, criada no dia 20 de agosto de 2003. Os assentados são provenientes dos municípios de Pombal (PB) e de Aparecida (PB), onde desenvolviam atividades agropecuárias nas fazendas da região como meeiros, trabalhadores sazonais ou como moradores (INCRA, 2010).
Figura 1 - Mapa do assentamento Jacu

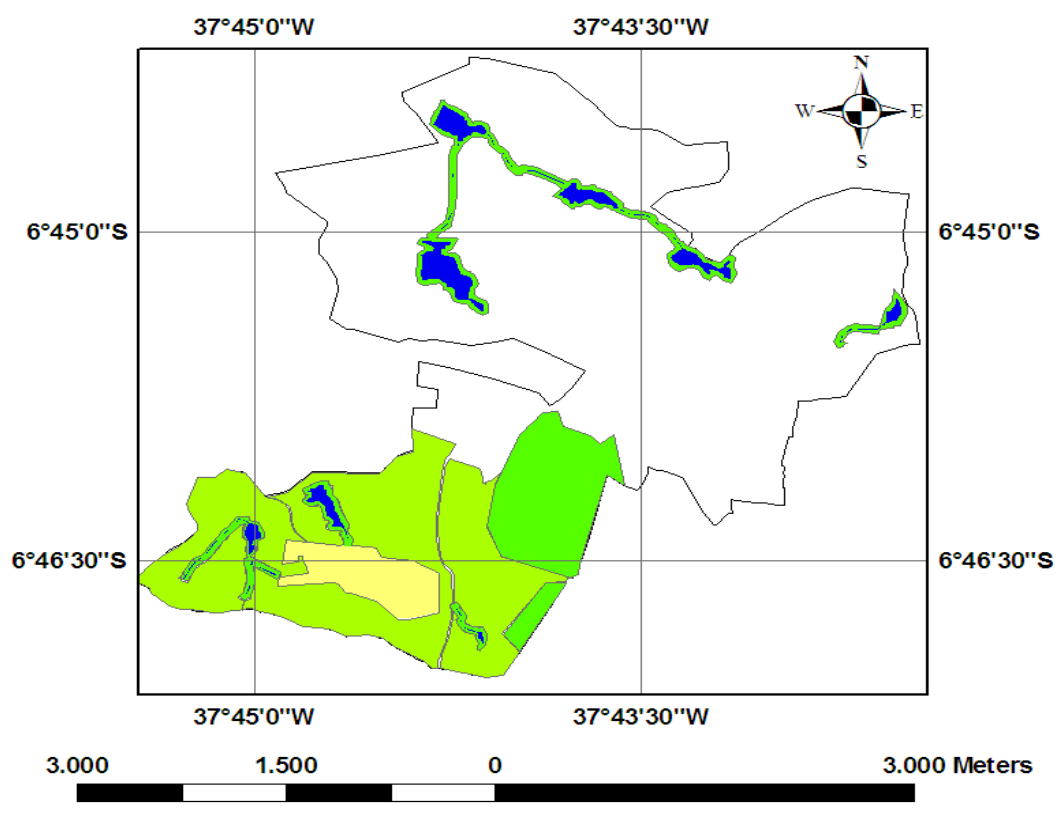

\begin{tabular}{|l||l|}
\hline CONVENÇÕES CARTOGRÁFICAS: & \multicolumn{2}{|c|}{ QUADRO DE ÁREAS (ha) } \\
RECURSOS_HIDRICOS & PERIMETRO: 1345.8387 \\
RESERVA_LEGAL & RECURSOS_HÍDRICOS: 30.197 \\
ÁREA_PARTICULAR & APP TOTAL: 129.334 \\
APPS & RESERVA LEGAL: 329.921 \\
\hline LIMITE_ASSENTAMENTO &
\end{tabular}

Fonte: Arquivo pessoal (2013)

No assentamento existem 6 açudes, 1 barragem subterrânea e 1 poço amazonas. Os recursos hídricos são usados para irrigação, cultivo de hortaliças e, especialmente, para abastecimento animal, o que acaba por comprometer o uso para consumo humano. A água utilizada para beber e cozinhar é retirada de cisternas de placa. Existem 39 cisternas no assentamento, construídas com recursos do Programa 1 Milhão de Cisternas (P1MC), com capacidade de armazenamento de $16 \mathrm{~m} 3$.

A vegetação do assentamento é composta por: Jurema-preta (Mimosa tenuiflora), Mofumbo (Combretumleprosum), Marmeleiro (Crotonblaquetianus), Angico (Anadenanthera colubrina), Aroeira (Myracrodruonurundeuva), Catingueira (Caesalpiniapyramidalis), Carnaúba 
(Coperniciaprunifera), Juazeiro (Ziziphus juazeiro), Jucá (Caesalpinia férrea), Jurema-branca (Piptadeniastipulacea), Jurema-preta (Mimosa tenuiflora), Mandacaru (Cerus jamacaru), Marmeleiro (Crotonsonderianus), Mufumbo (Combretumleprosum), Oiticica (Licania rigida), Pau-d'arco (Tabebuia serratifolia), Pereiro (Aspidospermapurifolium), Xiquexique, (Pilocereusgounellel).

\section{Impactos socioeconômicos das áreas de reserva legal e preservação permanente}

AARL do assentamento é de 329,92 ha, atendendo à legislação ambiental vigente. Há uma área desmatada dentro da $A R L$, de 3,847 ha, que é utilizada para plantio de lavoura de subsistência de 4 famílias que residem dentro da ARL, o que contraria a legislação vigente. As casas destas famílias foram construídas antes do parcelamento, portanto, não estava definida formalmente, a localização da ARL. Mesmo após o parcelamento, as casas localizadas dentro da ARL não foram retiradas.

Identificou-se processos de degradação na ARL. Da ARL é retirada lenha para uso doméstico, em média uma carroça por mês de árvores mortas por família, o equivalente a $1 \mathrm{~m}^{3}$; estacas e mourões, para infraestrutura dos lotes; além de servir para pastejo dos animais, no período chuvoso (Figura 2) Considerando que $70 \%$ das famílias do assentamento Jacu utilizam a ARL para a criação de animais, haveria uma redução de 230,9ha para a produção agropecuária, caso os assentados atendessem à legislação ambiental vigente.

De acordo com a Lei 12. 651, que dispõe sobre a proteção da vegetação nativa, no seu artigo $17, \S 1^{\circ}$, “Admite-se a exploração econômica da Reserva Legal mediante manejo sustentável, previamente aprovado pelo órgão competente do Sistema Nacional do Meio Ambiente (SISNAMA)". É permitida a coleta de produtos florestais não madeireiros, como frutos, cipós, folhas e sementes, observando os períodos de coleta; a época de maturação dos frutos e sementes; e técnicas que não coloquem em risco a sobrevivência de espécies, conforme o artigo 21, incisos I, II e III (BRASIL, 2012a).

As APPs do assentamento são compostas por serras com declividade maior que 45 graus, por matas ciliares dos riachos intermitentes e açudes que por estarem classificados como reservatórios artificiais devem ter uma APP de $30 \mathrm{~m}$, somando uma área total de 129,334ha. De acordo com o artigo $9^{\circ}$, da lei de proteção da vegetação nativa, "é permitido o acesso de pessoas e animais às áreas de preservação permanente para obtenção de água e para
Figura 2 - Extração de lenha e presença de animais na reserva legal

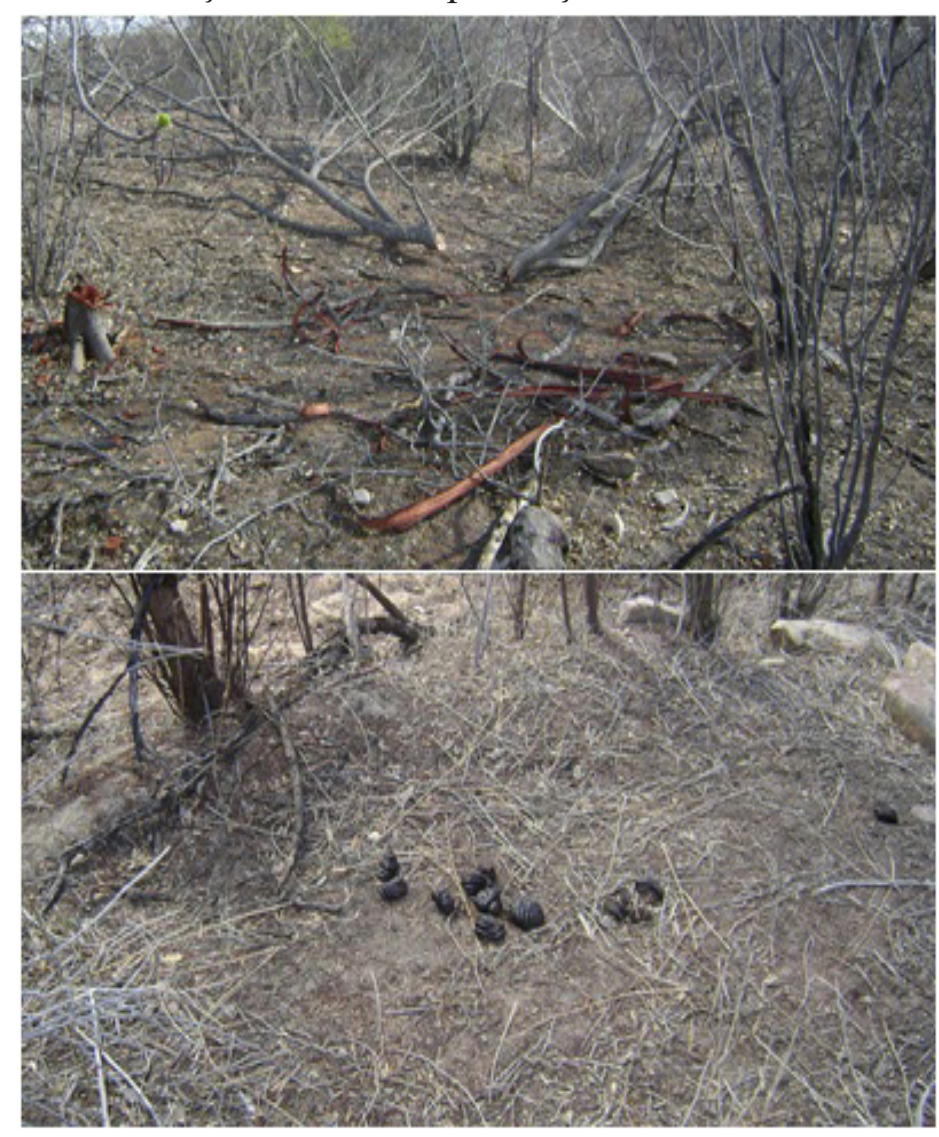

Fonte: Arquivo pessoal (2013)

realização de atividades de baixo impacto ambiental" (BRASIL, 2012a).

Constatou-se que as famílias do assentamento Jacu utilizam as APPs para o plantio de culturas anuais, como feijão e milho, e algumas frutíferas (Figura 3). A utilização destas áreas pode ser explicada pelo fato de se tratarem de áreas mais férteis, em virtude da umidade, e pela ocorrência de uso não planejado do processo produtivo do assentamento. A ausência dos órgãos ambientais de fiscalização e a pouca assistência técnica no assentamento são perceptíveis nas observações in loco e na fala das famílias assentadas.

Há uma predominância de cultivos tradicionais em regime de sequeiro, com destaque para o feijão e o milho, em seguida, vem a batata doce, o jerimum, e algumas frutíferas, banana, melancia e manga. O feijão e o milho são os produtos mais tradicionais da agricultura no assentamento, sendo 
Figura 3 - Famílias que utilizam as APPs para o cultivo no assentamento Jacu.

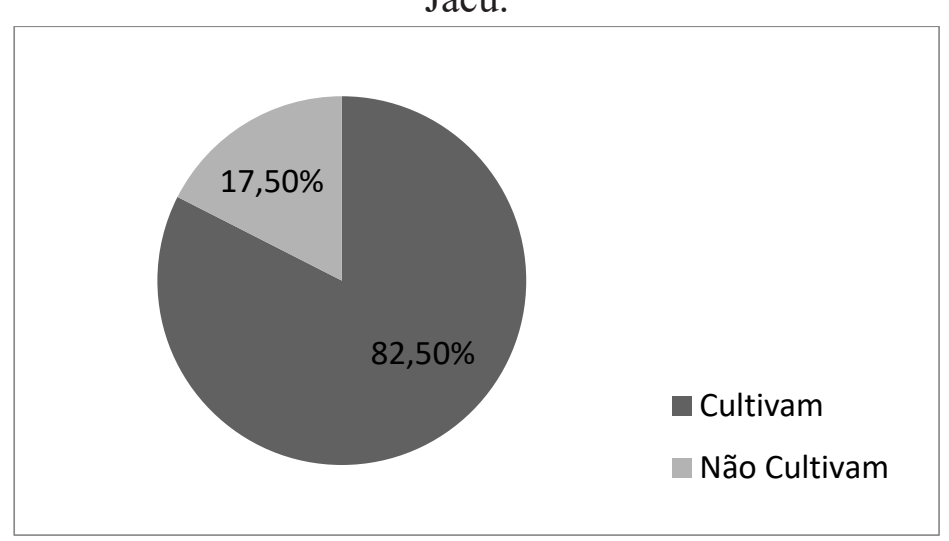

Fonte: Autoria própria (2014).

obtidos com base no trabalho familiar. É fato, que o sustento das famílias provém do que é produzido, por isso, precisam manter um potencial de produção que possa garantir o sustento de todos os membros da família.

As famílias destinam, em média, 1 ha para o cultivo de milho e 1 ha para feijão. A saca $(60 \mathrm{Kg})$ de milho era vendida a $\mathrm{R} \$ 30,00$ e a de feijão a R \$ 180,00, obtendo-se, em média, uma renda de R \$450,00/família e $\mathrm{R} \$ 2.700,00 /$ família, respectivamente. Se as famílias não produzissem em APPs, a parcela de área que deixaria de ser destinada para uso agrícola seria de 106,7 ha. Como 33 famílias assentadas cultivam nestas áreas, haveria um impacto de $\mathrm{R} \$ 14.850,00$ na produção de milho e de $\mathrm{R} \$ 89.100,00$ na produção de feijão, representando um impacto econômico expressivo na produção do assentamento.

Os produtos cultivados pelas famílias são comercializados em feiras livres e pelo Programa Compra Direta da Agricultura Familiar (PCDAF) (Tabela 1), no município de Pombal. As famílias assentadas também plantam capim para obtenção de pasto para os animais. O capim é plantado dentro do lote de cada agricultor e/ou nas áreas coletivas, destinando, geralmente, 1ha para cada família. Alguns, costumam alugar o pasto, chegando a obter R\$ 1.200,00/ mês.

${ }^{3}$ É um instrumento do Programa da Aquisição de Alimentos (PAA), instituído pela Lei $n^{\circ} 10.696$, de 02 de julho
de 2003, para incentivar a agricultura familiar, mediante a distribuição de produtos agropecuários para pessoas de 2003, para incentivar a agricultura familiar, mediante a distribuição de produtos agropecuários para
em situação de insegurança alimentar e para a formação de estoques estratégicos (BRASIL, 2012b).
Tabela 1 - Produtos comercializados no Assentamento Jacu.

\begin{tabular}{llrr}
\hline \multicolumn{1}{c}{ Produtores } & \multicolumn{1}{c}{ Produtos } & Quantidade (Kg) & Recursos (R\$) \\
\hline Ivanildo Ferreira de Almeida & Banana & $1.000,40$ & $2.000,80$ \\
José Moura Leite & Polpa de Frutas & 207,80 & 997,44 \\
José Ferreira Nobre & Banana Maçã & 213,63 & 469,99 \\
José Cavalcante da Silva & Mandioquinha & 620,00 & 868,00 \\
José de Arimateia L. da Silva & Cocada & 208,00 & $1.456,00$ \\
Francisco Monteiro Linhares & Cocada & 264,89 & $1.854,23$ \\
João Batista Carvalho da Silva & Polpa de Frutas & 330,45 & $1.586,16$ \\
Francinildo Soares Gomes & Manga & $1.346,25$ & $2.154,00$ \\
Francisco Flávio M. de Lima & Mamão & 40,52 & 64,83 \\
TOTAL & & $4.231,94$ & $10.583,45$ \\
\hline
\end{tabular}

Observação: Optou-se em manter os nomes dos assentados porque os dados são públicos e acessíveis a qualquer pessoa interessada.

As principais fontes de renda das famílias são provenientes da agricultura e da agropecuária. A pecuária baseia-se na criação extensiva de bovinos e de pequenos animais como caprinos e ovinos, para a produção de carne e leite, o leite produzido é utilizado na alimentação das famílias, sendo o excedente comercializado, porém com uma baixa produção, principalmente em função do manejo inadequado e das limitações climáticas. Algumas famílias têm acesso a benefícios sociais, como aposentadoria e principalmente, ao programa Bolsa Família, que ajuda na renda familiar.

Com a exigência de adequação às normas ambientais, perde-se parte considerável de área de cultivo, o que limita a produção e a diversificação das atividades rurais, e consequentemente, uma diminuição na renda. $\mathrm{O}$ cumprimento efetivo da legislação impulsionaria a busca de novas dinâmicas de organização, ocasionando a exploração intensiva dos recursos naturais, a exemplo, o desmatamento, aumento das queimadas, a fabricação de carvão, vendas da madeira de espécies nativas, a pesca predatória e até mesmo, o abandono do lote pelas famílias do assentamento.

\section{Assentamento Rural São João II}


O assentamento São João II é um projeto financiado pelo Programa Nacional de Crédito Fundiário (PNCF) e ocupa uma área de 266 ha (Figura 4). $O$ processo de aquisição durou 9 meses, sendo implementado no dia 22 de dezembro de 2001. O assentamento possui 15 famílias, antigos meeiros com experiência no exercício da agricultura, em lotes individuais de 17 ha. A compra da terra foi realizada pela Associação Comunitária de São João II, uma associação aberta a todos os moradores da comunidade São João. Posteriormente, no dia 5 de fevereiro de 2003, foi criada a Associação Comunitária dos Agropecuaristas do São João II.

Figura 4 - Mapa do assentamento São João II.

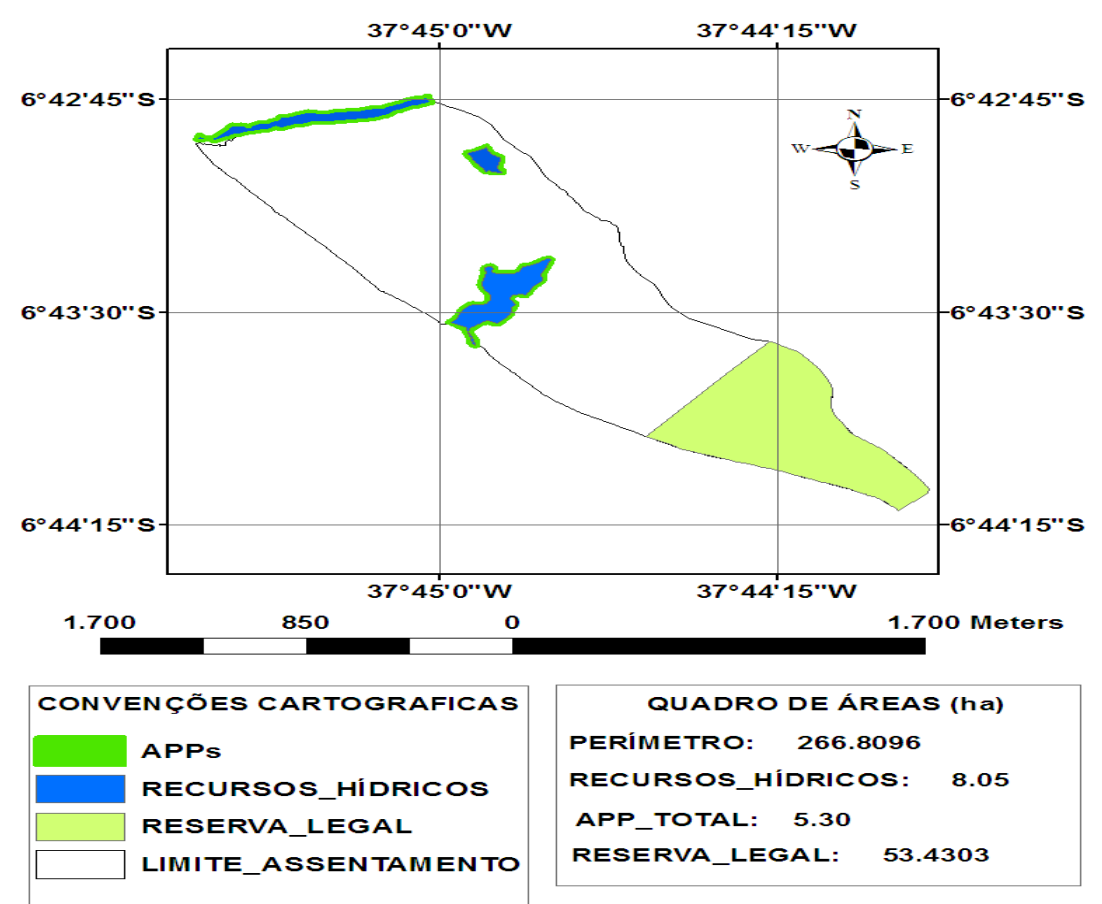

Fonte: Arquivo pessoal (2013).

O potencial hídrico do assentamento é bastante elevado devido ao rio Piranhas, que corta o assentamento. A água do rio é utilizada para a criação de animais e para o cultivo irrigado. Com relação às unidades de armazenamento de água do assentamento, existem 2 açudes, que são utilizados para o plantio de capim, criação de peixes e para dessedentação animal, há também 4 tanques de cimento, cada um com capacidade para
$96 \mathrm{~m}^{3}$, que foram adquiridos através do Projeto Cooperar. Os tanques são abastecidos com água do rio para irrigação de plantações próximas aos tanques.

As espécies vegetais encontradas no assentamento são: Jurema-preta (Mimosa tenuiflora), Mofumbo (Combretumleprosum), Marmeleiro (Crotonblaquetianus), Angico (Anadenanthera colubrina), Aroeira (Myracrodruonurundeuva), Catingueira (Caesalpiniapyramidalis), Cumaru (Amburana cearensis), Carnaúba (Coperniciaprunifera), Juazeiro (Ziziphus juazeiro), Jucá (Caesalpinia férrea), Jurema-branca (Piptadeniastipulacea), Jurema-preta (Mimosa tenuiflora), Mandacaru (Cerus jamacaru), Marmeleiro (Crotonsonderianus), Mufumbo (Combretumleprosum), etc.

\section{Impactos socioeconômicos das áreas de reserva legal e preservação permanente}

Da ARL do assentamento, de 53,4 ha, são extraídos estacas e mourões para a fabricação de cercas e toda infraestrutura dos lotes. No período chuvoso, os assentados utilizam a ARL para o pastejo dos animais, gerando vários conflitos, pois nem todos possuem animais e querem negociar "sua parte" na ARL (Figura 5). Sabendo que 48 \% das famílias do assentamento utilizam a ARL para a produção agropecuária, teria uma perda de 25,4 ha para a criação de animais, se os assentados atendessem efetivamente ao que recomenda a legislação ambiental.

Figura 5 - Pastejo animal na ARL do assentamento.

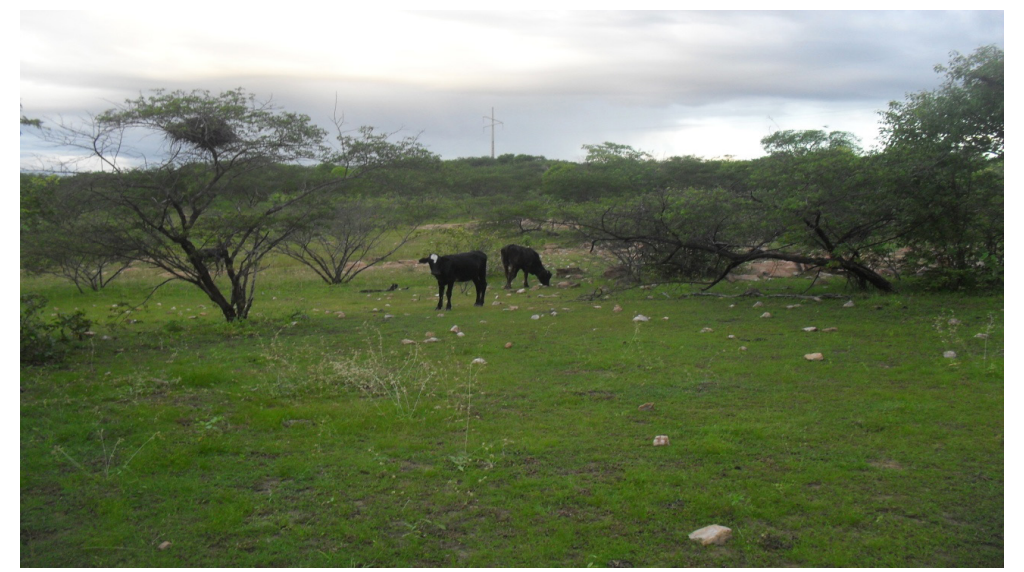

Fonte: Arquivo pessoal (2014).

As APPs do assentamento são compostas pelas faixas marginais do rio, 
riachos intermitentes e açudes, ocupando uma área de 5,3 ha. Os conflitos relativos à exploração dos recursos naturais podem estar associados à incerteza dos direitos de uso existentes, o que gera problemas: o desmatamento ilegal e a ineficiência da produtividade agrícola. As famílias utilizam as APPs, para o cultivo agrícola (Figura 6), por dois motivos. Primeiro, são áreas que apresentam os solos mais férteis do assentamento. Segundo, nota-se uma carência de acesso à assistência técnica e ao crédito, apesar da existência de programas como o Programa de Fortalecimento da Agricultura Familiar (PRONAF).

Figura 6 - Famílias que utilizam as APPs para cultivo no assentamento São João II.

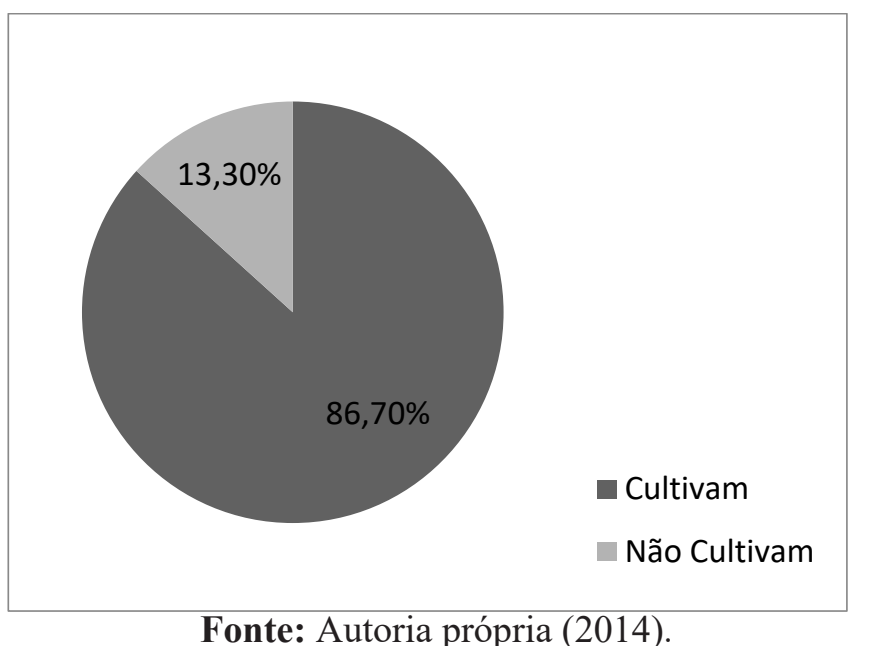

Fonte: Autoria própria (2014).

Nas APPs do assentamento são cultivadas frutíferas, como banana, goiaba, coco e maracujá; feijão e milho, semelhante ao assentamento Jacu. A área destinada ao plantio para as duas culturas é de 1ha, obtendo em média, uma renda por produção de milho, $\mathrm{R} \$ 300,00 /$ família e com o feijão $\mathrm{R} \$$ 1.800,00/família. Haveria uma redução de 4,6 ha destinada para a produção agrícola, caso as famílias não produzissem em APPs. Considerando que 13 famílias do assentamento cultivam nessas áreas, o impacto econômico na produção de milho seria de $\mathrm{R} \$ 3.900,00$ e de $\mathrm{R} \$ 23.400,00$ na produção de feijão, representando considerável redução na produção do assentamento.

Alguns assentados relataram que plantam capim para o consumo animal e costumam alugar o pasto como outra fonte de renda, destinando uma área de 1 ha, podem chegar a arrecadar R $\$ 1.200,00$ no período de 30 dias. A produção pecuária do assentamento baseia-se na bovinocultura extensiva, onde os índices produtivos são extremamente baixos, isso pode estar ligado ao manejo inadequado, refletindo-se diretamente na produção. Mas há também, uma criação de galinhas caipiras, muito apreciadas pela população local, que são consumidas pelas famílias e vendidas em feira livre e para clientes que conhecem os criadores e fazem encomendas.

A agricultura é uma das principais atividades econômica do assentamento, os assentados plantam culturas de sequeiro, no período chuvoso, entre fevereiro e abril: milho, feijão, arroz, gergelim, banana, mandioca; culturas irrigadas: milho, para comercialização em espiga, feijão, comercializado em vagem na feira livre e em programas sociais como PCDAF e a Comercialização Direta; e frutíferas: acerola, goiaba, manga e caju, que são beneficiados na agroindústria de polpa de frutas, implementada pelo Programa de Combate à Pobreza Rural (PCPR) do Projeto Cooperar do Governo Estadual.

Os agricultores entregam os produtos toda quarta-feira na sede da Secretaria de Trabalho e Ação Social do município, onde são pesados e separados, sob a supervisão de um técnico agrícola. Em seguida, é feita a emissão de notas fiscais para o futuro pagamento. Feita a separação, os produtos seguem para as entidades. O pagamento é feito com base nos preços utilizados pela Companhia Nacional de Abastecimento (CONAB) e nos preços de mercado (Tabela 2).

Tabela 2 - Preços dos produtos comercializados no PCDAF em Pombal-PB.

\begin{tabular}{lr}
\multicolumn{1}{c}{ Produtos $(\mathrm{kg})$} & Preço (R\$) \\
\hline Banana & 2,00 \\
Banana Maça & 2,20 \\
Cocada & 7,00 \\
Couve & 5,50 \\
Doce & 4,00 \\
Mamão & 1,60 \\
Mandioquinha & 1,40 \\
Manga & 1,60 \\
Milho & 4,00 \\
Polpa de frutas & 4,80 \\
\hline Fonte: Autoria própria $(2014)$.
\end{tabular}

Os assentados compram algumas frutas coletivamente, a exemplo 
da graviola, uva e umbu, entre outras, para complementar o processo agroindustrial, após a fabricação das polpas, as mesmas são comercializadas pelo PCDAF, e o lucro é dividido entre os assentados participantes da produção (SILVA, 2009). A Tabela 3 apresenta alguns dos produtos do assentamento São João II comercializados no PCDAF da prefeitura municipal de Pombal (PB), contemplados no período de 25/09/2013 a $31 / 12 / 2013$.

Tabela 3 - Produtos do Assentamento São João II.

\begin{tabular}{llrr}
\hline Produtores & Produtos & Quantidade $(\mathrm{Kg})$ & Recursos (R\$) \\
\hline Manuel José dos Santos & Doce & 212,00 & 848,00 \\
Damião Severino da Silva & Banana maçã & 642,53 & $1.413,57$ \\
Valdenor José da Silva & Cocada & 100,00 & 700,00 \\
Avanir do Nascimento Santos & Mandioquinha & 492,87 & 690,02 \\
Gildoesse dos Santos Ferreira & Couve & 128,90 & 708,95 \\
José Fernandes do Nascimento & Polpa de frutas & 435,04 & $2.088,19$ \\
TOTAL & - & $2.011,34$ & $6.448,73$ \\
\hline
\end{tabular}

Fonte: Pombal (2013)

Observação: Optou-se em manter os nomes dos assentados porque os dados são públicos e acessíveis a qualquer pessoa interessada.

As principais fontes de renda do assentamento provêm da agricultura e da pecuária. A viabilização social e econômica das famílias perpassa pela geração de políticas públicas que promovam melhorias, criando condições socioeconômicas para a permanência no campo. Com base nos dados apresentados, percebe-se que a adequação das pequenas propriedades à legislação ambiental vigente, causa impactos econômicos aos seus beneficiários, inviabilizando a atividade rural.

\section{Órgãos públicos de fiscalização socioambiental: A marca da ausência}

Os órgãos responsáveis pela fiscalização ambiental são ineficientes, em grande medida, pela falta de suporte institucional disponível e poucos agentes fiscalizadores, o que contribui para as falhas quando comprovado o uso indevido das ARLs e APPs (BASSO et al., 2011). Neste sentido, as ferramentas legais não são suficientes e eficientes quando se transpõe o que está definido nas leis para a realidade e cotidiano da zona rural, especialmente no que se diz respeito à correta forma de utilização, conservação e recuperação destas áreas (RODRIGUES et al., 2007).

Nos assentamentos rurais no Semiárido, os casos mais comuns de exploração dos recursos referem-se à extração de madeira em ARLs e a produção agrícola em APPs. No entanto, é preciso compreender estas práticas, como intervenções que procuram ser eficientes economicamente, ou a possibilidade de uma reprodução social coerente, e, por serem contrárias à legislação, não necessariamente são desprovidas de preocupação ambiental. Estas práticas podem também estar associadas à incerteza dos direitos de propriedade existentes nos primeiros anos da ocupação do assentamento, onde muitas famílias passaram a explorar os recursos indiscriminadamente (CUNHA e NUNES, 2008).

Nas visitas realizadas às Superintendências do INCRA e do IBAMA na Paraíba, e à gerência do Projeto Cooperar, através de conversas informais com seus representantes, observou-se que o limitado número de técnicos para realização das operações e atividades, a falta de recursos humanos, a dificuldade de acesso aos assentamentos para tratar a questão ambiental, a falta de políticas educativas, a pouca assistência técnica e a falta de fiscalização, causam uma morosidade por parte destes órgãos, o que acaba contribuindo para os desmatamentos ilegais e a utilização de forma inadequada das ARLs e das APPs.

A análise das atas dos assentamentos Jacu e São João II mostraram poucos registros de presença dos agentes do INCRA e do IBAMA. Estiveram presentes apenas no início da implantação dos assentamentos, o que pode contribuir para o desconhecimento da legislação ambiental por parte dos assentados. A leniência dos órgãos oficiais de fiscalização ambiental associada à falta de planejamento dos governos estaduais e federal inviabilizam as ações educativas e de fiscalização. Ao não possibilitarem a contratação de pessoal necessário ao funcionamento adequado, acabam contribuindo para a degradação da base de recursos naturais e para a ineficiência produtiva.

Embora os representantes dos órgãos pesquisados tenham informado que a comunicação com os assentamentos rurais é boa, na prática percebese, que essa interlocução é basicamente inexistente, visto que os técnicos visitam pouco os assentamentos. O que sugere que a legislação ambiental brasileira tende a fragilizar ainda mais os grupos sociais economicamente 
desfavorecidos, como os agricultores familiares, porque os órgãos públicos não realizam ações educativas e/ou informativas, quando muito fazem são fiscalizações que punem com multas ou embargos estes grupos.

\section{Considerações Finais}

As práticas socioambientais dos agricultores familiares pesquisados são orientadas pelas suas histórias de vida, seus valores e seus saberes. Isto reflete a diversidade das racionalidades que orientam a apropriação de recursos naturais, de modo que o lucro de uma pessoa pode representar a pobreza de outra e a degradação do meio ambiente é o resultado e uma das causas da exclusão social (GELZON e PAULSON, 2004). A legislação ambiental brasileira vem reforçando a ideia de exclusão ao beneficiar o madeiro que explora de modo sustentável e ao criminalizar as populações que são proibidas de coletar, caçar e pescar devido à criação das Florestas Nacionais (FLONA) e das Reservas Biológicas (REBIO) (LEROY, 2010; COELHO, CUNHA e WANDERLEY, 2010).

As questões locais, as práticas de grupos sociais e suas interações cotidianas nos espaços políticos formais se constituem elementos de tensionamento entre os agricultores familiares e a legislação ambiental e nos leva a fazer algumas indagações: A legislação ambiental leva em conta as práticas socioambientais e produtivas dos agricultores familiares? A preservação e a conservação das ARLs e das APPs são possíveis somente se os agricultores familiares abandonarem suas atividades agrícolas? Existem soluções técnicas para que os agricultores familiares continuem cultivando nessas áreas?

A análise das dinâmicas locais e nacionais são indispensáveis, mas é preciso introduzir o conceito de poder para se apreender as tensões entre as práticas socioambientais dos agricultores familiares e a legislação ambiental. Ao enfatizar os processos decisórios e o contexto social e econômico que moldaram a elaboração do Novo Código Ambiental Brasileiro e seus mecanismos de mitigação dos impactos ambientais, por exemplo, a ecologia política possibilita a compreensão de como se deu a distribuição e o controle dos recursos naturais.

Elias $(2001,2005)$ fornece os elementos necessários para se artircular natureza e política, sem sobreposições, a partir da análise das relações de interdependência existentes entre os diferentes grupos sociais, no caso agricultores familiares e grandes produtores, que defendem diferentes formas de regulamentação de acesso e uso das ARLs e das APPs. As interdependências são visualizadas na medida em que uma estratégia ambiental é formalizada. Os grandes produtores rurais e os madeireiros conseguiram ter ganhos com o Novo Código Ambiental Brasileiro, o que se refletiu nas práticas produtivas de grupos sociais extrativistas impedidos de coletar em FLONA e em REBIO, por exemplo.

Deste modo, qualquer mudança na legislação ambiental brasileira implicará na modificação das relações de interdependência. A articulação dos agricultores familiares, caçadores e coletores, por exemplo, na luta pela manutenção de suas práticas produtivas poderá interferi nas estratégias produtivas de grandes produtores rurais, madeireiros e mineradores, que se beneficiam, especialmente em termos econômicos, das políticas institucionais de mitigação de impactos ambientais nas áreas de seus empreendimentos. O que nos mostra que a questão ambiental é dinâmica e sua estrutura sujeita às relações de poder independentemente dos interesses e necessidades da coletividade.

\section{Referências Bibliográficas}

ALIMONDA, H. La ecologia política de Mariategui: buscando una herencia en Lima. Revista Tareas, Panamá, n. 125, p. 75-87, abr. 2007.

BASSO, V. M. et al. Avaliação da influência da certificação florestal no cumprimento da legislação ambiental em plantações florestais. Revista Árvore, Viçosa-MG, v.35, n.4, p.835-844, jul./ago. 2011.

BELMONTE, J. T. El proceso de monopolización del sistema agroalimentario mundial. Revista Ecología Política, n. 28, p. 61-67, jul./dic 2004.

BRANDENBURG, A. Ciências sociais e ambiente rural: principais temas e perspectivas analíticas. Revista Ambiente \& Sociedade, São Paulo, v.8, n.1. p. 1-14, jan./jun. 2005.

BRANDENBURG, A. Do Rural Tradicional ao Rural Socioambiental. Revista Ambiente \& Sociedade, Campinas, v. 13, n. 2. p. 417-428, jul./ dez. 2010. 
BRASIL. Presidência da República. Lei no 12.651, de 25 de maio de 2012a. Dispõe sobre a proteção da vegetação nativa; altera as Leis nos 6.938 , de 31 de agosto de 1981, 9.393, de 19 de dezembro de 1996, e 11.428, de 22 de dezembro de 2006; revoga as Leis $\mathrm{n}^{\mathrm{os}} 4.771$, de 15 de setembro de 1965 , e 7.754, de 14 de abril de 1989, e a Medida Provisória no 2.166-67, de 24 de agosto de 2001; e dá outras providências. Disponível em: $<\mathrm{http}: / / \mathrm{www}$. planalto.gov.br/ccivil_03/_Ato2011-2014/2012/Lei/L12651.htm>. Acesso em: 25 out. 2013.

Decreto $\mathrm{n}^{0} 7.775$, de 4 de julho de 2012b. Regulamenta o art. 19 da Lei ${ }^{0}$ 10.696, de 2 de julho de 2003, que institui o Programa de Aquisição de Alimentos, e o Capítulo III da Lei ${ }^{\circ} 12.512$, de 14 de outubro de 2011, e dá outras providências. Disponível em: $<$ http://www.planalto.gov.br/ ccivil_03/_ato2011 2014/2012/Decreto/D7775.htm>. Acesso em: 23 fev. 2014.

CAMPOS, S. A. C.; BACHA, C. J. C.O Custo Privado da Reserva Legal para os Produtores Agropecuários de São Paulo e Mato Grosso nos Anos de 1995 e 2006. Revista de Economia e Sociologia Rural, Brasília, v. 54, n.1, jan./mar. 2016.

CASTRO, L. F. C. GOMES, J. M. A. Atividades Agrícolas no Assentamento Iracema (PI) e suas repercussões sobre o Meio Ambiente. Interações, v. 8, n. 1, p. 65-73, mar. 2007.

COELHO, M. C. N.; CUNHA, L. H.; WANDERLEY, L. J. M. Conflitos em áreas de mineração na Amazônia: os casos dos quilombolas e dos moradores de beiras de lagos, dos canais fluviais e de estradas em Oriximiná. In: ZHOURI, A.; LASCHEFSKI, K. (Org.). Desenvolvimento e conflitos ambientais. Belo Horizonte: EDUFMG, 2010, p. 276-300.

CUNHA, L. H. Da "tragédia dos comuns" à ecologia política: perspectivas analíticas para o manejo comunitário dos recursos naturais. Revista Raízes, Campina Grande, v. 23, n. 01 e 02, p. 10-26, jan./dez. 2004.

CUNHA, L. H. e NUNES, A. M. B. Os desafios para a gestão de recursos comuns em assentamentos do semiárido. In: REUNIÃO BRASILEIRA DE ANTROPOLOGIA, 26., 2008, Porto Seguro. Anais... Porto Seguro: ABA, 2008. Disponível em: <http://www.abant.org.br/conteudo/... 26.../luis\%20 henrique\%20cunha.pdf $>$. Acesso em: 26 fev. 2014.

ELIAS, N. A sociedade de corte. Rio de Janeiro: Jorge Zahar, 2001. Introdução à sociologia. Lisboa: Edições 70, 2005.

FASIABEN, M. C. R. et al. Impacto Econômico da Reserva Legal Sobre Diferentes Tipos de Unidades de Produção Agropecuária. Revista de Economia e Sociologia Rural, Brasília, v. 49, n. 04, p. 1051-1096, out./ dez. 2011.

GARÍ, J. A. La ecología política de la biodiversidad. Revista Ecología Política, Barcelona, n. 20, p. 15-24, enero/jun. 2000.

GEZON, L. L. e PAULSON, S. Place, power, difference: multiscale research at the dawn of the twenty-first century. In: PAULSON, S.; GEZON, L. L. (Eds.). Political ecology across spaces, scales, and social groups. New Brunswick: Rutgers University Press, 2004, p. 1-16.

GÖRG, C; BRAND, V. Política ambiental global y competencia entre estados nacionales: sobre la regulación de la biodiversidad. Revista Ecología Política, Barcelona, n. 19, p. 67-87, jul./dic. 2000.

GREENBERG, J. B.; PARK, T. K. Political ecology. Journal of Political Ecology, Philadelphia, v. 1, n. 1, p. 1-12, Jan./June 1994.

HEINICH, N. A sociologia de Norbert Elias. Bauru: EDUSC, 2001.

INCRA. Plano de Desenvolvimento de Assentamento. Pombal, 2010.

LATOUR, B. As políticas da natureza: como fazer ciência na democracia. Bauru: EDUSC, 2004.

LEROY, J. P. Amazônia: território do capital e territórios dos povos. In: ZHOURI, A.; LASCHEFSKI, K. (Org.). Desenvolvimento e conflitos 
ambientais. Belo Horizonte: EDUFMG, 2010, p. 92-113.

MIRANDA, L. A.; CARMO, M. S. Recursos Florestais no Assentamento 12 de outubro (horto vergel), Mogi-Mirim, SP. Revista Árvore, Viçosa-MG, v.33, n.6, p.1085-1093, nov./dez. 2009.

MIRANDA, R. S. Ecologia política da soja e processos de territorialização da soja no Sul do Maranhão. 2011. 203f. Tese (Doutorado em Ciências Sociais) - Centro de Humanidades, Universidade Federal de Campina Grande, Campina Grande, 2011

. Impactos socioeconômicos das áreas de reserva legal e de preservação permanente sobre a produção agropecuária em assentamentos rurais. Projeto de pesquisa. Pombal: UFCG, 2013.4

MIRANDA, R. S.; CUNHA, L. H. H. Instituições sociais e a superação dos dilemas da ação coletiva em assentamentos rurais. Revista Agrária, São Paulo, n. 14, jan./jun. 2011.

NASCIMENTO, H. M. A questão ambiental na origem do problema agrário brasileiro e o caso da região Sul. Revista Economia \& Sociedade, Campinas, v. 17, n. 2, p. 103-132, ago. 2008.

POMBAL-PB. Secretaria do Trabalho e Ação Social. Relatório de Cumprimento de Objeto do Programa de Aquisição de Alimentos. Pombal-PB: fev., 2013.

QUINTANEIRO, T. The concept of figuration or configuration in Norbert Elias' sociological theory. Revista Teoria \& Sociedade, Belo Horizonte, v. 2, s/e, 2006. Disponível em: <http://socialsciences.scielo.org/pdf/s_tsoc/ v2nse/scs a02.pdf>. Acesso em: 23 dez. 2010.

RODRIGUES, E. R. CULLEN JR., L.; BELTRAME, T. P.; MOSCOGLIATO, A. V.; SILVA, I. C. Avaliação econômica de sistemas agroflorestais implantados para recuperação de reserva legal no Pontal do Paranapanema, São Paulo. Revista Árvore, v.31, n.5, p.941-948, Viçosa-MG, 2007.
SILVA, M. P. N. S. Assistência técnica e associativismo em assentamentos rurais do INCRA e do Crédito Fundiário. 2009. 81f. Monografia (Bacharelado em Agronomia) - Centro de Ciências e Tecnologia Agroalimentar, Universidade Federal de Campina Grande, Pombal, 2009.

VAYDA, A. P.; WALTERS, B. B. Against political ecology. Human Ecology Review, New York, v. 27, n. 1, p. 167-179, Mar. 1999. 